\title{
A experiência de uma família que vivencia a condição crônica por anemia falciforme em dois adolescentes
}

The experience of a family undergoing chronic condition for sickle cell disease in their two teens

Margani Cadore Weis', Mariana Roberta C. Barbosa², Roseney Bellato³ , Laura Filomena S. de Araújo4, Alessandra Hoelscher Silva ${ }^{5}$

\footnotetext{
${ }^{1}$ Graduada em Enfermagem pela Universidade Federal do Mato Grosso (UFMT) - Cuiabá (MT). margani_ufmt@yahoo.com.br

${ }^{2}$ Graduada em Enfermagem pela Universidade Federal do Mato Grosso (UFMT) - Cuiabá (MT).

marianac.barbosa@yahoo.com.br

${ }^{3}$ Doutora em Enfermagem pela Universidade de São Paulo (USP) São Paulo (SP), Brasil. Professora da Universidade Federal do Mato Grosso (UFMT) - Cuiabá (MT).

roseneybellato@gmail.com

${ }^{4}$ Doutora em Enfermagem pela Universidade de São Paulo (USP) Ribeirão Preto (SP), Brasil.; Professora da Universidade Federal do Mato Grosso (UFMT) - Cuiabá (MT). laurafil1@yahoo.com.br

${ }^{5}$ Mestre em Enfermagem pela Universidade Federal do Mato Grosso (UFMT) - Cuiabá (MT).

ale.hoelscher@yahoo.com.br
}

RESUMO: Estudo sobre a experiência de uma família que vivencia a condição crônica por anemia falciforme e que, ao tentar utilizar o SUS, necessitou, em algumas situações, acionar uma instância mediadora formal para garantir seu direito à saúde. O objetivo deste estudo foi compreender como os serviços de saúde têm participado do cuidado a pessoas com anemia falciforme e suas famílias. Estudo qualitativo com coleta de dados realizada por meio de História de Vida Focal e operacionalizada por entrevista em profundidade. Evidenciou-se que, mesmo existindo Políticas e Programas de atenção à saúde, cabe também aos profissionais se comprometerem para garantir o direito à saúde dessas pessoas.

PALAVRAS-CHAVE: Anemia falciforme; Doença crônica; Padrão de cuidado.

ABSTRACT: This study involves a family experiencing the chronic condition for sickle cell anemia of their two teens that needed to require, in some situations, a formal mediation to ensure their right to health when trying to use SUS' services. The objective of this study was to understand how health services have participated in the care of people with sickle cell anemia and their families. It is a qualitative study with data seizure by means of Focal Life Story and operationalized by in-depth interview. It became evidenced that, even when health care policies and programs are in force, professionals must also commit themselves to ensure those people the right to health.

KEYWORDS: Sickle cell anemia; Chronic disease; Standard of care. 


\section{Introdução}

Este estudo aborda a vivência de uma família com o adoecimento e o cuidado de dois adolescentes com anemia falciforme. O interesse por esse objeto de estudo - pessoas que vivenciam o adoecimento e cuidado por anemia falciforme - deve-se ao fato que, por ser uma condição crônica, conforme define a Organização Mundial da Saúde (2003), que compromete a vida de modo intenso desde tenra idade, traz inúmeras consequências também para a família da pessoa adoecida.

Trata-se da doença hereditária monogênica mais comum no Brasil, ocorrendo, predominantemente, entre afrodescendentes (CANÇADO; JESUS, 2007). Nas pessoas com o agravo, as hemácias adquirem forma de foice e, devido a essa configuração, não circulam adequadamente, causando a obstrução do fluxo sanguíneo capilar e também sua própria destruição precoce. Desse modo, os sinais clínicos observados são decorrentes dessa forma 'afoiçada' das hemácias, e as complicaçōes clínicas fazem parte diretamente da sua evolução, atingindo a maior parte dos órgãos e aparelhos (BRASIL, 2009). Dentre essas complicaçóes, algumas não reduzem a expectativa de vida da pessoa, mas comprometem consideravelmente a sua qualidade (ZAGO; PINTO, 2007).

A condição crônica pode ser vista por duas perspectivas: uma que envolve o sistema de saúde, sua organização e disponibilização de seus recursos, sendo denominada perspectiva macro; e a perspectiva micro, que considera o cotidiano das famílias ao gerenciar o cuidado necessário à pessoa adoecida (BELLATO et al., 2011b). Nesta dimensão, a condição crônica refere-se a uma experiência de vida que envolve problemas de saúde, requerendo gerenciamento contínuo por um período de vários anos ou décadas (OMS, 2003).

Segundo Silva et al. (2002), a doença de uma pessoa também é doença de sua família, pois os laços de afetividade presentes na estrutura familiar são responsáveis pelo envolvimento de todos os seus entes no enfrentamento da doença. Assim, concordando com Bellato et al. (2011), considera-se que as pessoas e suas famílias desenvolvem seu próprio cuidado com criatividade e grande potencial cuidativo, mesmo na ausência de profissionais de saúde. Mas, para aumentar-lhes esse potencial, o que essas pessoas necessitam, mais do que "treinamento" para fazer o que já fazem, o que as pessoas têm carência é de práticas efetivas por parte dos profissionais, apoiando-as em seu próprio cuidado (BELLATO et al., 2011a).

Diante da condição crônica por anemia falciforme, a importância do estudo permeia a possibilidade de contribuir para a visualização e compreensão de problemas atuais do Sistema Único de Saúde (SUS) no que diz respeito à atenção às pessoas e famílias que vivenciam essa condição, comumente apontada como uma questão de saúde pública brasileira, em virtude de sua prevalência e morbimortalidade. O objetivo é compreender, a partir da experiência de uma família que vivencia a condição crônica por anemia falciforme de dois adolescentes, o modo como os serviços e profissionais de saúde têm participado do cuidado a essas pessoas.

\section{Metodologia}

Estudo de caso com abordagem qualitativa (MINAYO, 2010) sobre uma família que vivencia uma condição crônica por anemia falciforme em dois adolescentes.

A busca pelo participante do estudo atendeu aos seguintes critérios de seleção: ser a criança/adolescente usuária do SUS; e ter a família, em algum momento da busca pelo cuidado, acionado uma instância jurídica ou de participação social do SUS para requerer, formalmente, a efetivação do direito à saúde há, no mínimo, um ano, de modo a compreender como essa instância afetou a experiência da família.

A aproximação com a família se deu por meio de uma associação de portadores de anemia falciforme, onde foi indicada uma família composta de três pessoas vivenciando tal agravo - o pai e os dois filhos -, e sendo a mãe portadora do traço falciforme. No primeiro encontro, os pais assinaram o Termo de Consentimento Livre e Esclarecido, cientes da garantia do anonimato da família, dos profissionais e instituições.

A coleta de dados foi realizada nos meses de janeiro a maio de 2011, utilizando como estratégia metodológica a História de Vida Focal, que possibilita a descoberta, exploração e avaliação de como as pessoas 
compreendem seu passado, unindo sua experiência individual a seu contexto social, interpretando e dando significado às suas experiências (BELLATO et al., 2008). Para isso, utilizou-se a entrevista em profundidade do tipo aberta, a partir de uma questão norteadora inicial: "Conte-nos o que vocês vivenciam e como vivenciaram os acontecimentos que surgiram na vida da familia desde o início do adoecimento dos filhos". Indagações subsequentes foram realizadas de maneira a aprofundar e explorar a experiência do adoecimento e cuidado. Além disso, utilizou-se a observação de campo e elaborou-se o diário de campo.

Após leitura dos dados, elegeram-se unidades de significados e, a partir destas, constituiu-se o eixo de análise "Trajetória de busca por cuidado: sobrecarga do cuidado familiar" e elaborou-se o desenho da "Trajetória empreendida pela família na busca pelo cuidado", abrangendo o período de 1993 a 2011 dessa busca.

O desenho da trajetória é uma das ferramentas do Itinerário Terapêutico e permite visualizar as redes de sustentação e apoio tecidas pela família que possam lhes dar certo suporte na experiência de adoecimento, bem como explorar as buscas por cuidado nos diferentes sistemas de cuidado (ARAÚJO; BELLATO, 2011).

Propóe-se, por meio do desenho da trajetória, compreender o modo como tem sido realizada a busca e o gerenciamento do cuidado, dando destaque à rede formal de apoio a família da qual fez parte, também, a Ouvidoria do Estado de Mato Grosso, acionada para a garantia do direito à saúde dos adolescentes. O desenho da trajetória foi subdividido em três fases, conforme temporalidade marcada pelos pais dos adolescentes, e as setas enumeradas representam os movimentos de busca por cuidado de maneira sequencial nessas três fases da trajetória.

O estudo respeitou as prerrogativas éticas em pesquisa com seres humanos, conforme Resolução 196/CNS/1996. É um estudo vinculado à Pesquisa Matricial "As instituiçôes de saúde e do poder judiciário como mediadores na efetivação do direito à saúde: análise de itinerários terapêuticos de pessoas/famílias no SUS/MT", sob a responsabilidade do Grupo de Pesquisa Enfermagem, Saúde e Cidadania (GPESC) da Faculdade de Enfermagem da Universidade Federal de Mato Grosso (FAEN/ UFMT). O projeto matricial ao qual este estudo se vincula foi aprovado pelo Comitê de Ética em Pesquisa sob o protocolo 671/CEP-HUJM/09.

\section{Resultados e discussão}

As narrativas obtidas nos encontros compuseram o desenho da trajetória de busca por cuidado para os dois adolescentes, nas diversas fases de seus processos de adoecimento individual. Desse modo, elas foram agrupadas e compuseram a categoria que recebeu a definição "Trajetória de busca por cuidado: a sobrecarga no cuidado familiar". A família do estudo foi nomeada como "Família Soneto" e o núcleo de análise centra-se nos pais - Assis, 40 anos, com Anemia Falciforme e Clarice, 34 anos, portadora do traço falciforme - e nas duas crianças - Olavo, 14 anos e Cecília, 13 anos, ambos com Anemia Falciforme. A busca pelo cuidado iniciou-se após o nascimento da primogênita, Cora; a Figura 1 mostra a primeira fase da experiência de adoecimento e cuidado vivenciada pela família Soneto.

Aos seis meses de idade, Cora começou a apresentar febre, choro constante e inchaço nas articulaçóes. Os pais procuraram vários serviços de saúde sem obter respostas conclusivas sobre a doença da filha, apenas maneiras de controlar a dor que a criança sentia (Figura 1, seta 1).

À época, 1994, não havia programas de saúde que estabelecessem um protocolo de atendimento a pessoas com doença falciforme. Apenas em 1996, o Ministério da Saúde, visando à necessidade de melhorar o atendimento, criou o Programa de Anemia Falciforme (PAF), que dispóe, dentre outros, sobre o diagnóstico precoce, a prevenção das complicaçóes da doença, a detecção dos portadores de traços falciformes e as açóes educativas aos profissionais de saúde e à população (BRASIL, 1996).

Salienta-se que o bom atendimento às pessoas acometidas por essa condição é dependente, também, do conhecimento dos profissionais para que saibam reconhecer e buscar recursos que facilitem o diagnóstico. Os pais repetiram várias vezes que há falta de preparo dos profissionais de saúde para reconhecer os sinais e sintomas da anemia falciforme, prorrogando, dessa forma, o diagnóstico de seus filhos. Somente após várias crises e internaçóes, a família encontrou o Dr. 


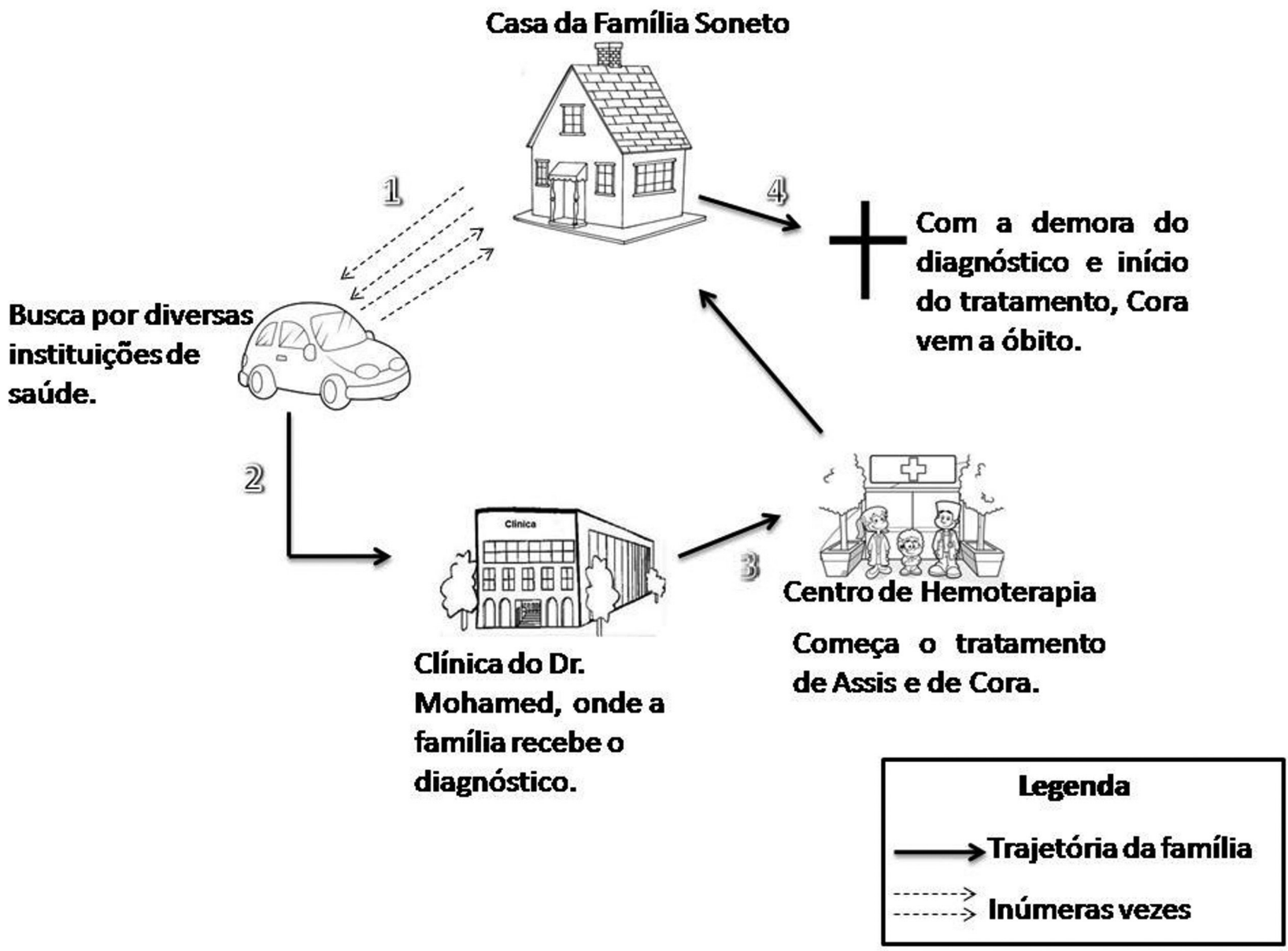

Mohamed, médico pediatra em um dos hospitais em que procuraram atendimento e que conseguiu diagnosticar o agravo (Figura 1, seta 2): "Esse médico foi o doutor Mohamed. Falou comigo, e foi, e olhou ela. Quando ele avaliou, ele foi e pediu uma junta médica (...) Ai, ele foi e pediu um exame (...) E ai comprovou que ela tinha anemia falciforme" (Clarice).

A família, entáo, foi referenciada a um centro de hematologia estadual, onde Cora e seu pai iniciaram o acompanhamento (Figura 1, seta 3). Assis não sabia que tinha anemia falciforme, pois, quando jovem, havia recebido o diagnóstico de reumatismo em decorrência das dores que sentia e, portanto, fazia tratamento para essa patologia. Já para Cora, embora com acompanhamento, a demora no diagnostico contribuiu para instauração de complicações irreversíveis que levaram ao seu óbito com um ano e quatro meses de idade (Figura 1, seta 4): "Começou a ter parada cardíaca, ela teve duas vezes (...) Ela passou mal, na terceira vez ela foi a óbito, que a gente nem conseguiu chegar com ela até o hospital. Então nós perdemos ela." (Clarice).

Após dois anos da morte de Cora, os pais planejaram uma nova gestação; foi então que nasceu Olavo, hoje com 14 anos de idade. Menos de um ano depois 
Figura 2. Convivendo com a anemia falciforme

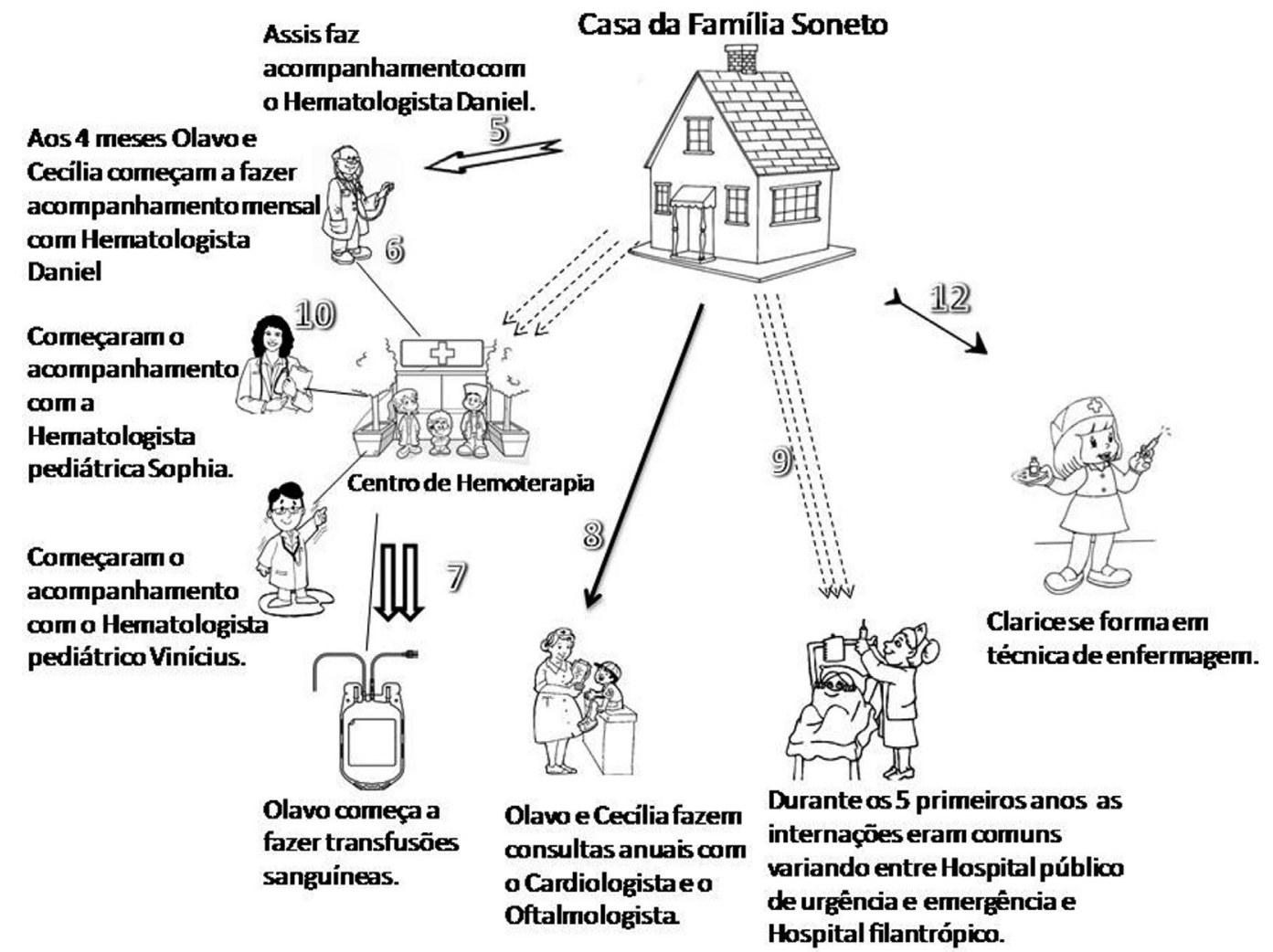

BARBOSA, M. R. C.; WEIS, M. C. Comivendo coma Anemia Falciforme, 2011.

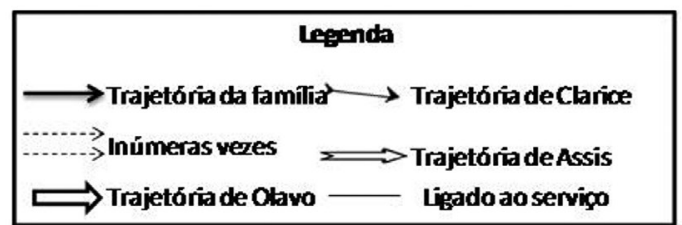

nasceu Cecília, sendo que essa gestação não foi planejada pelo casal.

Destaca-se que, somente em 2001, o Ministério da Saúde criou o Programa Nacional de Triagem Neonatal (PNTN) para que todos os recém-nascidos tenham a garantia de confirmação diagnóstica precoce, acompanhamento especializado por equipe multidisciplinar em serviços de referência em triagem neonatal e tratamento adequado à doença, conforme o fornecimento dos insumos terapêuticos necessários (BRASIL, 2011).

A Figura 2 explora a segunda fase da experiência de adoecimento e cuidado da família Soneto, quando se iniciou uma série de rearranjos no seu cotidiano para conviver com a condição crônica dos filhos e tentar prestar um cuidado que pudesse suprir as necessidades que eles apresentavam. Segundo Nascimento et al. (2005), ao se fazer presente na infância, a condição crônica acarreta demasiadas dificuldades, entre elas: hospitalizaçóes por longos períodos, diversas internaçôes, separação dos membros da família, atividades diárias interrompidas, compreensão limitada do diagnóstico, dificuldade financeira, dor, ansiedade, aflição e medo da possível morte.

As duas crianças receberam o diagnóstico de anemia falciforme assim que completaram quatro meses 
de idade, quando começaram a apresentar os primeiros prováveis sintomas: "Aí as crianças nasceram e tudo mais, eles tiveram a síndrome pé e mão, né, que começou a inchar as articulações dele" (Assis). A síndrome mão-pé (dactilite) se inicia com necrose da medula óssea das porçóes distais dos membros e é acompanhada de evidentes sinais inflamatórios, com edema e calor (ZAGO; PINTO, 2007).

A família procurou por ajuda profissional no centro especializado onde o pai realizava acompanhamento, já que agora conheciam acerca do agravo (Figura 2, setas 5 e 6). Olavo começou a ter acompanhamento mensal com necessidade de transfusôes sanguíneas frequentes (Figura 2, seta 7) e Cecília, ao completar quatro meses, também iniciou o acompanhamento no mesmo centro, porém, sem a necessidade de transfusóes. Com três anos de idade começaram a fazer consultas ambulatoriais anuais com cardiologista e oftalmologista (Figura 2, seta 8).

Durante os primeiros cinco anos, mesmo tendo o acompanhamento do hematologista Daniel no centro especializado, Olavo apresentou recorrentes complicaçốes que acarretam inúmeras internações em diferentes hospitais públicos da cidade de Cuiabá (Figura 2, seta 9): "Olavo, na época, até ele completar os cinco aninhos, a gente era quase visita em casa e morava mais no hospital (...). Ele tinha muitos quadros de pneumonia, era bronquite alérgica" (Clarice). O período com maior ocorrência de óbitos e complicaçóes graves decorrentes da anemia falciforme estende-se até o quinto ano de vida, sendo que os cuidados profiláticos representam a essência do tratamento, do mesmo modo que, diante da ocorrência de um evento agudo, é a abordagem clínica e o modo como esses cuidados são ofertados que irão determinar o melhor ou pior prognóstico (BRASIL, 2009b).

Em 2002, iniciaram o tratamento com a hematologista e pediatra Sophia para receberem um acompanhamento mais específico (Figura 2, seta 10). Porém, segundo a família, essa médica não atendeu às necessidades das crianças, levando-os a procurar outro profissional, Dr. Vinícius, que os acompanha mensalmente desde essa data (Figura 2, seta 11): "A gente ia atrás e ela começou a mentir (...) E foi até que um dia o meu cunhado ligou pra ela e perguntou (...) se ela não ia. Ai ela falou que ela não ia porque ela náo recebia pelo SUS pra tá no Pronto Socorro" (Clarice).

Conforme Cecílio (2011, p. 591):

A dimensão profissional do cuidado é aquela que se dá no encontro entre profissionais e os usuários e nucleia o território da micropolitica em saúde [...] Essa dimensão é regida por três elementos principais, que lhe conferem sua maior ou menor capacidade de produzir o bom cuidado: a) a competência técnica do profissional no seu núcleo profissional especifico, ou seja, a capacidade que tem, por sua experiência e formação, de dar respostas para o (s) problema (s) vivido (s) pelo usuário; b) a postura ética do profissional, em particular, o modo com que se dispóe a mobilizar tudo o que sabe e tudo o que pode fazer, em suas condiçóes reais de trabalho, para atender, da melhor forma possivel, tais necessidades; c) não menos importante, a sua capacidade de construir vínculo com quem precisa de seus cuidados.

Além de todos os desarranjos estruturais que a família sofria, por vezes ainda se via frente a profissionais que não estavam dispostos a produzir o bom cuidado ou, até mesmo, algum cuidado, a despeito de saberem que essa postura acarretava uma série de transtornos e sobrecarga aos cuidadores.

Cecília e Olavo precisaram de outros cuidados em razão das constantes internaçóes pelas complicaçóes mais frequentes nessa fase. Esse apoio foi ofertado pela família ampliada de Assis e Clarice, envolvendo as três geraçóes, de modo a tentar suprir as necessidades apresentadas. Além dos pais, os avós maternos, Oswald e Tarsila, e a tia materna, Lygia, passaram a participar do cuidado sempre que necessário. Para Nóbrega et al. (2010, p.430): "A condição crônica na infância afeta as relaçôes familiares, transformando-se numa doença de família. A necessidade de cuidados permanentes e as internaçóes hospitalares atingem pais, filhos, irmãos".

Teve dia da minha irmã deixá filho, deixá família. (...) Ela deixô com a minha mäe, deixou 
tudo e veio ficar comigo. (...) E, assim, graças a Deus, a gente também tem uma família bem compreensiva, né. Amor. Que a gente encontrava muito apoio. Eles ajudavam a gente bastante (Clarice).

Pudemos evidenciar que o cuidado familiar foi mais intensamente assumido pelas mulheres da família materna, ainda não residindo no mesmo município. Alguns estudos mostram que a maioria dos cuidadores é do sexo feminino e que, em situações de enfermidade, está sócio e culturalmente determinado que a mulher, sendo a provedora do cuidado, deve assumir o papel de cuidadora principal. Isso está ideologicamente determinado, constituindo uma condição moral (NEVES; CABRAL, 2008; AMENDOLA; OLIVEIRA; ALVARENGA, 2011).

Percebe-se que, embora os dois adolescentes apresentem uma mesma enfermidade genética, as manifestaçóes clínicas são bastante diferenciadas, acarretando, consequentemente, diferentes necessidades de cuidado. Assim, o cuidado dispensado a Olavo e Cecília é produzido e buscado de forma distinta pela família, para um e para outro: "Eu tenho duas crianças em casa com o MESMO [ênfase] problema de saúde, mas que manifesta de uma forma totalmente uma diferente da outra" (Clarice).

Os indivíduos manifestam ampla diversidade de manifestaçôes clínicas, mesmo apresentando a mesma doença genética, pois ela pode seguir cursos clínicos extremamente variáveis. Enquanto uns apresentam complicaçóes graves, outros são pouco sintomáticos ou praticamente assintomáticos. As complicaçôes surgem subitamente, variando em gravidade entre populaçóes, entre sujeitos de uma mesma população e na mesma pessoa em diferentes fases da vida (CANÇADO, 2007).

Para a família Soneto, tais complicaçóes exigiram reorganização constante do cuidado para um e outro filho, e a principal responsável por isso foi Clarice, pois, além de desempenhar seu papel de mãe, esteve presente, juntamente com o pai, em todos os momentos de busca e gerenciamento desse cuidado. Procurando aprimorar e ampliar o cuidado oferecido aos seus filhos, Clarice se profissionalizou no curso de Técnico de Enfermagem em 2004, mas não se inseriu no mercado de trabalho, pois o objetivo de sua formaçáo foi exclusivamente o cuidado de seus filhos (Figura 2, seta 12):

Uma coisa que pode ser evitada e não é porque você não encontra profissional pra tá ali presente. E, ai foi aonde eu resolvi fazer esse curso, não com a intenção de sair pro campo pra trabalhar, mas pra mim poder cuidar melhor dos meus filhos em casa (Clarice).

Segundo Almeida et al. (2006), a sobrecarga do cuidado recai na mãe, principal cuidadora da criança com um problema crônico de saúde, fazendo com que ela passe a criar estratégias para lidar com os novos contextos e exigências de cuidado. Isso pode representar um estímulo para que a mãe se sinta mais capaz e aberta à aprendizagem.

Clarice entende que a sua formação como técnica de enfermagem a auxiliou, também, nas buscas por cuidado junto aos serviços e profissionais, inclusive suprindo seu conhecimento em relação à anemia falciforme, por ter ela própria esse conhecimento, tanto teórico quanto decorrente de sua vivência com os filhos.

Você tá na busca de informaçóes o tempo todo, pra que quando você chegar numa unidade e dependendo do profissional (...) não tem informação, você sabe como correr, você sabe como cobrar, quem você exigir, como você buscar apoio (Clarice).

A mãe cita que, em diversas internaçóes dos seus filhos, os profissionais não lhes prestaram assistência de forma eficaz, despertando a vontade de melhorar o que as crianças recebiam e, ao mesmo tempo, diminuindo a necessidade de internaçóes para controle da dor.

Então, assim, ai acontecia muito, assim, anoitecia e o pessoal ia dormir, ai perdia o soro. A gente não sabia o que fazer, procurava as meninas [refere-se a enfermeiras e técnicas de enfermagem] e não encontrava. Ai ele inchava e ficava, sabe? E a gente, você como mãe, fica até louca no corredor do hospital, procurando 
Figura 3. Período pós-complicações da anemia falciforme

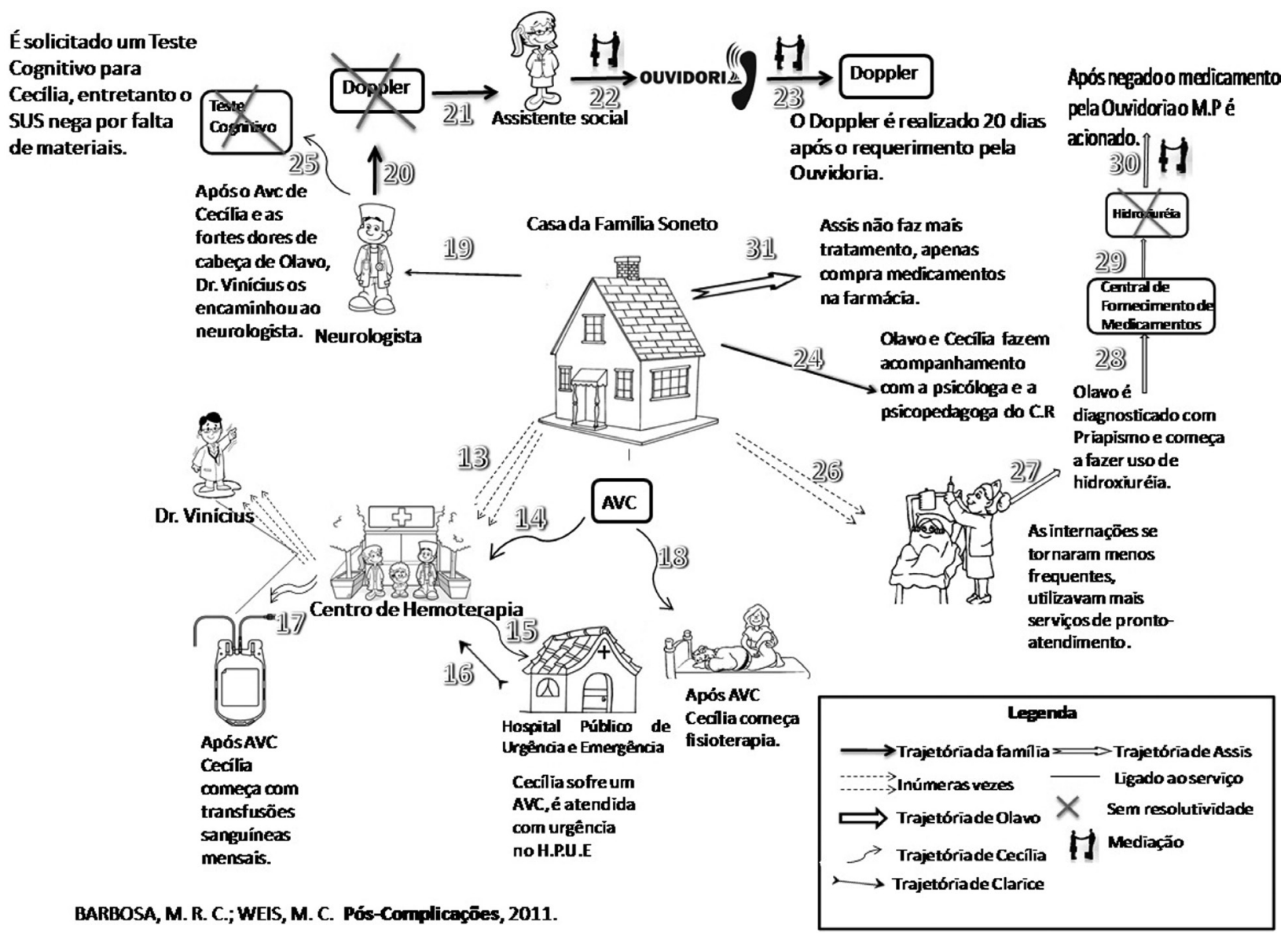

alguém pra te ajudar e você náo encontra (Clarice).

Grande parte dos profissionais de saúde não está preparada para o atendimento à pessoa com Anemia Falciforme como o recomendado, faltando conhecimento para enfrentar tal situação (RODRIGUES; ARAUJO; MELO, 2010).

Todo cidadão tem direito a um atendimento que alcance suas necessidades de saúde, e isso é assegurado pela Constituição Federal, segundo o artigo 198, inciso II - atendimento integral, com prioridade para as atividades preventivas, sem prejuízo dos serviços assistenciais (BRASIL, 1988). Segundo Mattos (2004), defender a integralidade nas práticas significa que a oferta de açóes deve estar sintonizada com o contexto específico de cada encontro. A equipe que atende deve ser capaz de identificar a doença que causa o sofrimento manifesto, mas não deve reduzir a pessoa à doença que lhe provoca tal sofrimento. Portanto, se as práticas profissionais se mostrarem mais resolutivas frente às necessidades de saúde das pessoas, a família terá mais apoio no cuidado de seu membro adoecido, sem precisar se profissionalizar.

Após sua profissionalização, Clarice se sentiu mais segura e assumiu, inclusive, a administração de algumas terapêuticas, tanto em momentos de crise como nos finais de semana e madrugada. Quando necessário, a prescrição era feita por telefone pelo médico Hematologista 
e, no dia seguinte, a família procurava o centro de hemoterapia para consulta, conforme relata a mãe:

$E$ hoje, assim, quando ele entra em crise, nós sempre temos a tabelinha de remédios que podem em duas, em duas horas podemos dar um tipo de remédio. Se isso não resolver, ai tem que procurar outro (Clarice).

Com as experiências vividas, os pais das crianças com anemia falciforme aprendem a reconhecer as crises de dor e a preveni-las, como também administrar medicações analgésicas. Aprendem, ainda, como reconhecer sinais de infecção, infarto cerebral, entre outras, todas importantes para o bem estar e sobrevivência da criança (RODRIGUES; ARAUJO; MELO, 2010).

$\mathrm{Na}$ experiência de adoecimento dessa família, houve um período de buscas mais intensas pelos serviços de saúde devido a complicaçóes no estado de saúde dos adolescentes, o que caracteriza a terceira fase da experiência de adoecimento e cuidado da família Soneto.

Apesar de certa estabilidade na manifestação da doença, em 2007, Cecília, aos nove anos, sofreu um Acidente Vascular Encefálico (AVE) em casa, que a mãe denomina de Acidente Vascular Cerebral (AVC). A mãe, ao perceber o que estava ocorrendo, contatou o pai e ambos levaram Cecília para o centro de hemoterapia; mas não havia médico e a família foi encaminhada ao hospital público de urgência e emergência (Figura 3, setas 14 e 15).

Se for colocar, assim, numa balança, ela foi uma criança que praticamente não deu trabalho pra gente. (...) Ela fazia as consultas de rotina, os exames de rotina todo mês, mas ela tava sempre bem. Então, quando aconteceu o $A V C$, pra nós, assim, foi uma surpresa muito grande, porque ELE [Olavo, ênfase] apresentava muito mais problemas de saúde do que ela (Clarice).

Ao chegar ao hospital, o médico plantonista que atendeu Cecília desconsiderou a possibilidade de o ser AVE aventado pela mãe, alegando que a sintomatologia da doença era apenas dor. A mãe, dotada de seus conhecimentos, insistiu com o médico sobre essa possibilidade, na tentativa de conseguir o atendimento que sua filha precisava, segundo relata:

Doutor, mas a minha filha tem anemia falciforme e ela pode tá tendo um AVC. E ele falava assim: - Não, anemia falciforme não dá $A V C$, anemia falciforme dá DOR [ênfase]. Ai eu falava assim: - Doutor, não faz isso doutor! Minha filha tá tendo um AVC e ela precisa ser transfundida com urgência (Clarice).

Estudos mostram que as complicaçóes neurológicas afetam $25 \%$ das pessoas com anemia falciforme, dentre elas o AVE é o mais comum, e, na infância, geralmente, é resultante da oclusão das artérias intracranianas. Por isso, os pais devem ser orientados durante as consultas de rotina a como reconhecer precocemente os sinais dessa complicação e a procurar assistência profissional em caso de suspeita. $\mathrm{O}$ atendimento hospitalar deve preconizar a realização de um hemograma e prova cruzada, pois, se confirmado, o paciente possivelmente necessitará de uma transfusão sanguínea. Após a estabilização do quadro, é necessária a realização de exames de imagem para a confirmação do diagnóstico. Se confirmado, pais ou pacientes devem ser orientados sobre a rotina de transfusão regular. Porém, na maioria das vezes, o médico da emergência não tem preparo para a especificidade da anemia falciforme, e a falta de profissionais capacitados na sala de emergência acaba resultando em abordagens diferentes do manejo das complicaçóes (RODRIGUES, 2008).

Ao desconsiderar a possibilidade do AVC na criança com anemia falciforme, o profissional infringiu o direito à saúde, garantido constitucionalmente à criança:

É dever da família, da sociedade e do estado assegurar com absoluta prioridade à Criança e ao Adolescente, o direito à vida, à saúde, alimentação, à educação, ao lazer, à profissionalização, à cultura, à dignidade, ao respeito, à liberdade e à convivência familiar e comunitária, além de colocá-lo a salvo de toda forma 
de negligência, discriminação, exploração, violência, crueldade e opressão (BRASIL, 1988).

Além de a Constituição assegurar o direito à saúde das crianças, em 13 de julho de 1990 entrou em vigor o Estatuto da Criança e do Adolescente (ECA), nos termos:

A garantia de prioridade a receber proteção e socorro em quaisquer circunstâncias; à precedência de atendimento nos serviços públicos ou de relevância pública; à preferência na formulação e na execução das politicas sociais públicas; à destinação privilegiada de recursos públicos nas áreas relacionadas com a proteção à infância e à juventude (BRASIL, 2008, p.10).

Persistindo a negativa do médico em atender Cecília, seus pais entraram em contato por telefone com o Dr. Vinícius, que explicou o caso ao plantonista; só então este decidiu por transfundir a criança. Porém, no hospital não havia a unidade de sangue necessária nem veículo disponível para buscá-la no centro de hemoterapia; restou aos pais providenciar a busca do hemoderivado para ser administrado na filha (Figura 3, seta 16). Posteriormente, no momento da transfusão, a mãe enfatizou que a técnica de enfermagem iria infundir a unidade de sangue em temperatura não adequada e, segura dos conhecimentos adquiridos com sua profissionalização, ela interviu, conseguindo evitar que isso acontecesse, não sem mais um constrangimento, agora com a profissional de enfermagem, conforme relata:

Pois bem! Você é a profissional, mas antes de qualquer coisa eu sou máe e eu sei o que eu to te falando. E se a minha filha pegar uma contaminação, você será responsável! Porque não se faz o que você acabou de fazer" (Clarice).

Após o AVE, as necessidades de saúde de Cecília mudaram, exigindo transfusôes sanguíneas mensais, fisioterapia e acompanhamento anual com neurologista (Figura 3, setas 17 e 18). Entretanto, esse acompanhamento foi inconstante devido à dificuldade em conseguir as consultas, tendo que aguardar durante meses por uma vaga no Sistema Único de Saúde (SUS).

A partir de 2007, Cecília foi a duas consultas com o neurologista e Olavo, a apenas uma, devido a fortes dores de cabeça. $\mathrm{Na}$ primeira consulta, o neurologista solicitou para os dois adolescentes um Doppler Transcraniano (Figura 3, seta 19), método não invasivo que utiliza a técnica de ultrassom para medir indiretamente o fluxo nas porçóes proximais das principais artérias intracranianas, proporcionando informaçóes dinâmicas da circulação cerebral (ZÉTOLA, et al., 2006). No entanto, a Secretaria Estadual de Saúde negou a realização desse exame (Figura 3, seta 20), alegando não haver vagas em virtude do elevado número de solicitaçóes e de profissional disponível para realizá-lo. Clarice e Assis, então, receberam a orientaçáo da assistente social do centro de hemoterapia (Figura 3, seta 21) para procurar a Ouvidoria do SUS (Figura 3, seta 22), que funciona como um canal entre o indivíduo, que exerce seu papel de cidadáo, e a gestão pública de saúde, com estratégias para melhora dos serviços prestados pelo SUS (BRASIL, 2007). Lá, conseguiram uma resposta satisfatória e, em menos de 20 dias, o exame for realizado (Figura 3, seta 23):

\section{Eai, quando você se depara com as dificuldades do sistema, aí você via o quanto valia. Então, assim, a gente com toda uma constituição, com deveres, com igualdades, mas que na verdade... (Clarice).}

$\mathrm{Na}$ experiência da condição crônica, a necessidade de cuidado se amplia e se diversifica, sendo que a família, não encontrando respostas efetivas às suas necessidades ou a resolutividade esperada junto aos serviços e profissionais de saúde, vê-se obrigada a lançar mão do poder judiciário para garantir seu direito à saúde por meio de demandas judiciais (BELLATO et al., 2011b), gerando o fenômeno designado 'judicialização da saúde' (GANDINI et al., 2008).

Os pais relataram, ainda, que o desenvolvimento escolar dos filhos foi prejudicado devido às inúmeras internações, exames e consultas mensais, resultando, até mesmo, em reprovaçóes. Os dois foram encaminhados 
à psicóloga e psicopedagoga e fizeram acompanhamento durante dois anos (Figura 3, seta 24).

Em outubro de 2009, o hematologista Vinícius solicitou nova avaliação neurológica para Cecília, que só foi realizada em janeiro de 2011, quando foi solicitado, também, um teste cognitivo, negado pelo SUS sob a alegação de falta de kit utilizado pela psicóloga para realizá-lo (Figura 3, seta 25): "Não conseguiu! Não. Pelo SUS não tem, porque o governo não manda o kit pra psicólogo"(Clarice).

Em dezembro de 2009, Olavo começou a apresentar crises de priapismo, também decorrentes da anemia falciforme e, ao procurarem por assistência, depararam-se novamente com o desconhecimento dos profissionais, que não entendiam a gravidade do caso (Figura 3, setas 26 e 27). O priapismo é definido como uma ereção peniana prolongada e persistente (com mais de 4 horas de duração), frequentemente dolorosa, desencadeada ou não por estímulo sexual. Caracteriza-se como uma situação clínica de emergência, por isso requer um diagnóstico rápido (CFM, 2006). A mãe, ciente da urgência da situação, relatou a situação:

Ela falou assim: - Mas mãe, aqui só tá atendendo. O médico só vai vir aqui se for de urgência! Ai falei: - Mas do meu filho é urgência! O meu filho tem anemia falciforme e ele tá tendo uma crise de priapismo, é atendimento de urgência! Não sei se é do seu conhecimento, mas o caso do meu filho é de urgência! (Clarice).

Em março de 2010, Olavo iniciou o uso da medicação Hidroxiuréia (Figura 3, seta 28), que age aumentando a concentração de hemoglobina fetal e confere benefícios como a diminuição da aderência dos eritrócitos, leucócitos e plaquetas ao endotélio vascular e da viscosidade sanguínea, contribuindo para a diminuição dos fenômenos inflamatórios e vaso-oclusivos (FIGUEIREDO, 2007).

Em 2002, o Ministério da Saúde aprovou o uso de Hidroxiuréia para pessoas com Anemia Falciforme, sendo a dispensação desse medicamento de responsabilidade das Secretarias de Saúde dos Estados da Uniâo e Distrito Federal (BRASIL, 2002).

Porém, mais uma vez o direito a saúde da família não foi respeitado, pois, em janeiro de 2011, a central de medicamentos deixou de disponibilizar o medicamento e, em março, a família entrou novamente com processo na Ouvidoria para requerer o fármaco. Como foi negado, acionou-se o Ministério Público de Mato Grosso, conforme relata a mãe (Figura 3, setas 29 e 30):
Porque ele já tinha sete meses fazendo uso da medicação. Então esse periodo que ele tá sem o remédio, regride o tratamento dele. Quando ele começa de novo é como se ele voltasse à estaca zero (Clarice).

Para Bellato et al. (2011), o modo de atuação do poder judiciário é limitado e marcado temporalmente, ou seja, a resposta judicial não atende à necessidade de cuidado continuado, prolongado e constantemente renovado ao se vivenciar a condição crônica de adoecimento.

A vivência cotidiana da família Soneto, marcada pela experiência da condição crônica em decorrência da anemia falciforme e pelas muitas exigências de cuidado a cada ente adoecido, foi expressa na fala da mãe, Clarice, nos termos:

É tão imprevisivel. Então, de repente, assim, já houve situaçóes, várias situaçóes de a gente tá aqui tranquilo, a gente tá brincando, assistindo filme junto, tá curtindo um ao outro ou então a gente saiu, fez um lanche gostoso, ai deitou pra dormir. PRONTO! [Ênfase na fala] No outro dia, tudo diferente. Porque aí tá tudo dividido, o meu marido de um lado com filho, eu do outro lado com outro filho. E assim, parece assim que sua vida vira de cabeça pra baixo. Ai você acaba, querendo ou não, você depende da familia né, você precisa de alguém pra tá ajudando e, assim, TUDO TINHA MUDADO. Então, a gente, hoje, nós APRENDEMOS viver todos os dias aproveitando um pouquinho do outro. A gente não sabe até que dia né?! Até quando. Vive o hoje! (Clarice).

A vida de uma família que vivencia a condição crônica por anemia falciforme pode ser bastante inconstante, seja pelas possibilidades de agravamento da 
doença, as incertezas do amanhã, as necessidades de cuidado constantemente modificadas, as dificuldades para instituir certa normalidade em seu cotidiano; seja pela incerteza de se obter atenção integral e resolutiva dos profissionais e serviços de saúde a cada busca por cuidado que a família empreender na tentativa de atender às necessidades de saúde de seus diferentes entes.

\section{Conclusão}

A vivência da Família Soneto, aqui apresentada, possibilitou compreender o quanto a condição crônica por anemia falciforme afetou a todos, necessitando que buscassem modos de cuidado próprio para cada um dos adolescentes. Mas, sobretudo, nos permitiu apreender que os serviços e profissionais de saúde ainda têm participado de maneira pouco implicada nesse cuidado, principalmente se considerada a necessidade de um acompanhamento contínuo e permanente como o requerido por essa condição, o que acarretou sobrecarga e desgastes de inúmeras ordens para essa família.

Percebemos que, ainda que haja Políticas e Programas estabelecidos para organizar práticas de gestão e de atenção às pessoas com anemia falciforme, por si só, estes não garantem um atendimento eficaz e integral segundo o que é preconizado, pois cabe também aos profissionais se comprometerem e se responsabilizarem para que tais políticas e programas encarnem práticas concretas que possam, de fato, garantir o direito à saúde dessas pessoas e suas famílias.

\section{Referências}

ALMEIDA, M. I. et al. Cuidados complexos de mãe de criança com doença crônica. Revista de Enfermagem Escola Anna Nery, v.10, n.1, p. 36-46, 2006

AMENDOLA, F.; OLIVEIRA, M.A.C.; ALVARENGA, M.R.M. Influência do apoio social na qualidade de vida do cuidador familiar de pessoas com dependência. Revista da Escola de Enfermagem da USP, v.45, n.4, p.889-889, 2011.

ARAÚJO, L. F. S.; BELLATO, R. Itinerários terapêuticos na abordagem de experiências de cuidado no ensino de enfermagem. Referência, Coimbra, Portugal, v.2, p.492, 2011. Suplemento.

BELLATO, R. et al. A história de vida focal e suas potencialidades na pesquisa em saúde e em enfermagem. Revista Eletrônica de Enfermagem, v.10, n.3, 2008

BELLATO, R. et al. Mediação e mediadores nos itinerários terapêuticos de pessoas e famílias em Mato Grosso. In: PINHEIRO, R.; MARTINS, P. H. (orgs.). Usuários, redes sociais, mediações e integralidade em saúde. Rio de Janeiro: CEPESC: IMS/UERJ: EDITORA UNIVERSITÁRIA UFPE - ABRASCO, p.177-183, $2011 \mathrm{a}$.

"Remédio jurídico" e seus afetamentos no cuidado de uma família. In: PINHEIRO, R.; MARTINS, P.H. Rede de Pesquisa Multicêntrica "Incubadora da Integralidade-redes e mediações". Rio de Janeiro: ABRASCO, p.193-201, 2011 b.
BRASIL. Constituição (1988). Constituição da república Federativa do Brasil. Brasília, DF: Senado, 1988.

Ministério da Saúde. Departamento de Atenção Especializada. Manual de educação em saúde. Linha de Cuidado em Doença Falciforme, Brasília, vol.2, p.36, 2009a. (Série A. Normas e Manuais Técnicos). Disponível em: <http://www.cehmob.org. br/downloads/Linha_de_CuidadoDF_Manual_MS.pdf>. Acesso em: 4 mai. 2011.

Ministério da Saúde. Departamento de Atenção Especializada. Manual de eventos agudos em doença falciforme. Brasília: Editora do Ministério da Saúde, p.50, 2009b. Disponível em: $\quad$ <http://bvsms.saude.gov.br/bvs/publicacoes/manual_ eventos_agudos_doenca_falciforme.pdf>. Acesso em: 18 jun. 2011.

Ministério da Saúde. Diagnóstico situacional do programa nacional de triagem neonatal. Brasília, DF: Secretaria de atenção à saúde, p.4, 2011.

Ministério da Saúde. Estatuto da Criança e do Adolescente. 3. ed. Brasília: Editora do Ministério da Saúde, 2008.

Ministério da Saúde. Oficinas Glossário Temático Ouvidoria do SUS. Brasília, DF: Secretária de Gestão Participativa, p. 48, 2007. 
Ministério da Saúde. Programa de anemia falciforme. Brasília, DF: Secretária de Assistência à Saúde, 1996.

Ministério da Saúde. Protocolo Clínico e Diretrizes Terapêuticas - Doença Falciforme - Hidroxiuréia. Portaria n. 872 do Ministério da Saúde, 2002.

CANÇADO, R.D. Doenças falciformes. Prática hospitalares. Ano IX, n. 50, mar./abr., 2007.

CANÇADO, R.D.; JESUS, J.A. A doença falciforme no Brasil. Revista Brasileira de Hematologia e Hemoterapia, v.29, n.3, p.203-206, 2007.

CECILIO, L.C.O. Apontamentos teórico-conceituais sobre processos avaliativos considerando as múltiplas dimensões da gestão do cuidado em saúde. Interface. Comunicação Saúde Educação, v.15, n.37, p.589-99, 2011.

CONSELHO FEDERAL DE MEDICINA. Associação Médica Brasileira. Projeto Diretrizes: Priapismo. Sociedade Brasileira de Urologia, p.16, 2006.

FIGUEIREDO M. S. Agentes indutores da síntese de hemoglobina fetal. Revista Brasileira de Hematologia e Hemoterapia, v.29, n.3, p.313-315, 2007.

GANDINI, J. A. D.; BARIONE, S. F.; SOUZA, A. E. A Judicialização do Direito à Saúde: a obtenção de atendimento médico, medicamentos e insumos terapêuticos por via judicial: critérios e experiências. Revista Biblioteca Digital Juridica, Brasília, 24 mar. 2008. Disponível em: <http://bdjur.stj.gov.br/dspace/handle/ 2011/16694>. Acesso em: 24 jun. 2010.

MATTOS, R.A. A integralidade na prática (ou sobre a prática da integralidade). Cadernos de Saúde Pública, Rio de Janeiro, v.20, n.5, p.1411-1416, set/out, 2004.

MINAYO, M. C. S. O desafio do conhecimento. Pesquisa qualitativa em saúde. 12. ed. São Paulo: HUCITEC, 2010. 407p.
NASCIMENTO, L. C.; ROCHA, S. M. M.; HAYES, V. H.; LIMA, R. A. G. Crianças com câncer e suas famílias. Revista da Escola de Enfermagem da USP, v.39, n.4, p.469-474, 2005.

NEVES, E.T; CABRAL, I. E. Emponderamento da mulher cuidadora de crianças com necessidades especiais de saúde. Texto e Contexo Enfermagem, Florianópolis, v.17, n.3, p.552-60, 2008.

NÓBREGA, R.D. et al. Criança em idade escolar hospitalizada: significado da condição crônica. Texto e Contexto Enfermagem, Florianópolis, v.19, n.3, p.425-433, 2010.

ORGANIZAÇÃO MUNDIAL DA SAÚDE. Cuidados inovadores para condições crônicas: componentes estruturais de ação: relatório mundial/OMS. Brasília, DF: Ministério da Saúde, 2003.

RODRIGUES, C.C.M.; ARAUJO, I.E.M.; MELO, L.L. A família da criança com doença falciforme e a equipe enfermagem: Revisão crítica. Revista Brasileira de Hematologia e Hemoterapia, v.32, n.3, p. 257264, 2010.

RODRIGUES, C.C.M. Urgências e Emergências em Doença Falciforme: Um desafio para a enfermagem. Prática Hospitalar, Ano X, n.56, mar./abr., 2008.

SILVA, L.F.; et al. Doença crônica: o enfrentamento pela família. Acta Paulista de Enfermagem., v.15, n.1, jan./mar., 2002.

ZAGO, M.N.; PINTO, A.C.S. Fisiopatologia das doenças falciformes: da mutação genética à insuficiência de múltiplos órgãos. Revista Brasileira de Hematologia e Hemoterapia, v.29, n.3, p.207-214, 2007.

ZÉTOLA, V.F. et al. Doppler transcraniano na prática neurológica. Arquivos de Neuropsiquiatria, v.64, n.1, p.100-103, 2006.

Recebido para publicação em fevereiro de 2013

Versão definitiva em novembro de 2013

Suporte financeiro: não houve

Conflito de interesse: inexistente 